\title{
Metabolic and hormonal studies in patients with essential hypertension
}

\author{
W. JANUSZEWICZ, M. CISWICKA-SZNAJDERMAN, B. WOCIAL, \\ M. SZNAJDERMAN, H. IGNATOWSKA-SWITALSKA, H. BERENT, \\ Z. ZUKOWSKA-GROJEC, AND T. FELTYNOWSKI
}

From the Second Department of Medicine, Academy of Medicine, 59 Nowogrodzka Street, 02-006 Warsaw, Poland

In 106 patients with essential hypertension and different plasma renin activity several hormonal and metabolic factors were studied: urinary excretion of catecholamines, blood levels of cholesterol and triglycerides, levels of glycaemia and insulinaemia after glucose load and plasma fibrinolytic activity. The plasma renin activity in 46.2 per cent of patients was normal, whereas in 25.5 per cent it was low, and in 28.3 per cent it was high. In patients with high plasma renin activity the excretion of noradrenaline and adrenaline was relatively high while that of dopamine was low. Significantly lower triglyceride levels were found in patients with low plasma renin activity in comparison with those with high and normal plasma renin activity. There was also a statistically significant difference in the euglobulin lysis time which was shortest in patients with low and longest in patients with normal plasma renin activity. The results of the study show that patients with different plasma renin activity may also differ in some hormonal and metabolic values.

It has been shown recently that patients with essential hypertension do not represent a homogeneous population in relation to humoral factors (Brunner et al., 1972; DeQuattro and Miura, 1973; Laragh, 1973; Januszewicz and Wocial, 1975). Particular attention has been paid to the observation that patients with essential hypertension differ in relation to plasma renin activity. It was found that the activity of this enzyme was normal in about 50 to 60 per cent of patients, while in others it was low or high (Brunner et al., 1972; Crane et al., 1972). Brunner et al. (1972, 1973) suggested that patients with different plasma renin activity differed also in relation to the clinical course of hypertension and the incidence of cardiovascular complications. Though this interesting observation was not confirmed by other authors (Doyle et al., 1973; Mroczek et al., 1973) it gave an impetus for further research to elucidate the relation between humoral factors and the clinical course of essential hypertension.

The aim of the present work was to investigate some metabolic and hormonal factors in patients with essential hypertension and different plasma renin activity.

Received for publication 7 February 1977

\section{Patients and methods}

The investigations were carried out in 106 patients with essential hypertension, 41 women and $65 \mathrm{men}$, aged 19 to 59 years. The diagnosis of essential hypertension was based on the clinical picture and special laboratory tests and radiological methods to exclude secondary forms of hypertension. All patients were in hospital and remained on a standard diet. They did not receive any hypotensive drugs and other drugs which might have influenced the values for at least 3 weeks before the study.

Plasma renin activity was measured by radioimmunoassay of angiotensin I using CEA-IRESORIN kits. The patients were divided into 3 groups on the basis of plasma renin activity; the arithmetic mean of plasma renin activity obtained in the control group of 20 healthy people \pm 1 SD was accepted as a criterion of division; 49 patients $(46 \%)$ were defined as having normal plasma renin activity, 27 patients $(26 \%)$ had low, and 30 patients $(28 \%)$ had high plasma renin activity. The mean age in all groups was similar. The known duration of hypertension was 7.4 years in the normal renin group and 5.2 and 5.6 years in the low and high renin groups, respectively. The mean haematocrit 
values were $43.9 \pm 4.2$ in the normal renin group, $44.4 \pm 3.6$ in the low renin group, and $44.3 \pm 4 \cdot 1$ in the high renin group and they did not show statistical differences.

The basic data related to the 3 groups of patients are presented in the Table.

In all patients the following investigations were done: (1) urinary excretion of noradrenaline and adrenaline according to the method of Von Euler and Lishajko (1961) and urinary excretion of dopamine according to Carlsson and Waldeck (1958); (2) serum levels of cholesterol using the method of Theorell (Cramer and Isaksson, 1959) and triglyceride using the enzymatic method with Boehringer tests; (3) plasma immunoreactive insulin levels and glucose tolerance test after oral glucose load (Somogyi, 1952); (4) fibrinolytic activity measured by dilute blood clot lysis time (Fearnley et al., 1957) and euglobulin lysis time (Niewiarowski, 1960).

The results were statistically evaluated using Student's $t$ test; the accepted level of significance was $\mathrm{P}<0.05$.

\section{Results}

The urinary excretion of noradrenaline and adrenaline was lowest in patients with low plasma renin activity (Fig. 1). The highest noradrenaline excretion was seen in patients with high plasma renin activity. The differences in noradrenaline excretion between high renin and normal renin groups as well as between high renin and low renin groups were statistically significant. There was also a statistically significant difference between adrenaline in high and low renin groups. In comparison with the control group, a statistically significant difference in urinary noradrenaline excretion was seen only in patients with low plasma renin activity. The differences in urinary excretion of adrenaline between patients and controls were not significant.

In contrast to the noradrenaline excretion, the urinary excretion of dopamine was highest in the low renin group and lowest in the high renin group.

Table 106 patients with essential hypertension (41 women, 65 men) age 19-59 years

\begin{tabular}{|c|c|c|c|}
\hline & $\begin{array}{l}\text { Normal } \\
\text { PRA }\end{array}$ & $\begin{array}{l}\text { Low } \\
\text { PRA }\end{array}$ & $\begin{array}{l}\text { High } \\
\text { PRA }\end{array}$ \\
\hline $\begin{array}{l}\text { No. of cases } \\
\text { Mean age }(y)\end{array}$ & $\begin{array}{l}49(46 \%) \\
36 \cdot 6\end{array}$ & $\begin{array}{l}27(26 \%) \\
38 \cdot 1\end{array}$ & $\begin{array}{l}30(28 \%) \\
36 \cdot 3\end{array}$ \\
\hline $\begin{array}{l}\text { Mean plasma renin } \\
\text { activity (ng/ml per } \mathrm{h} \text { ) }\end{array}$ & $2 \cdot 3 \pm 0.97$ & $0.2 \pm 0.06$ & $6 \cdot 3 \pm 4 \cdot 81$ \\
\hline
\end{tabular}

PRA, plasma renin activity.
The differences were statistically significant (Fig. 2). The dopamine excretion was significantly lower in patients with normal and high plasma renin activity than in the control group.

The level of triglycerides was significantly lower in patients with low plasma renin activity in comparison with the remaining groups, while the level of cholesterol was the highest in patients with normal plasma renin activity (Fig. 3). It should be noted that both triglyceride and cholesterol levels

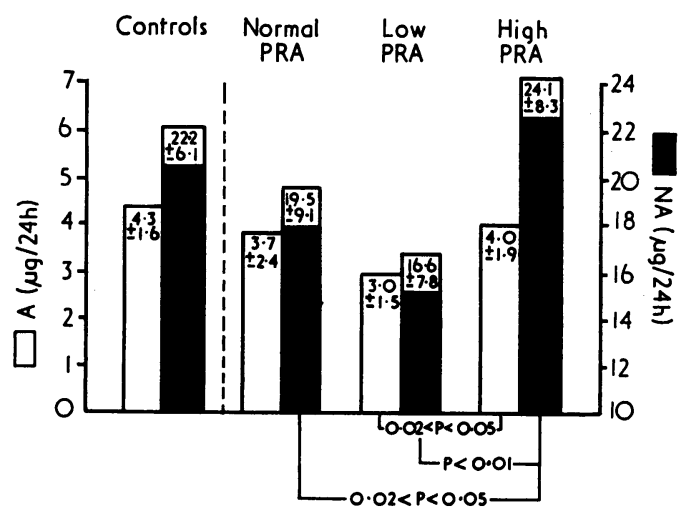

Fig. 1 Mean urinary adrenaline $(A)$ and noradrenaline (NA) excretion.

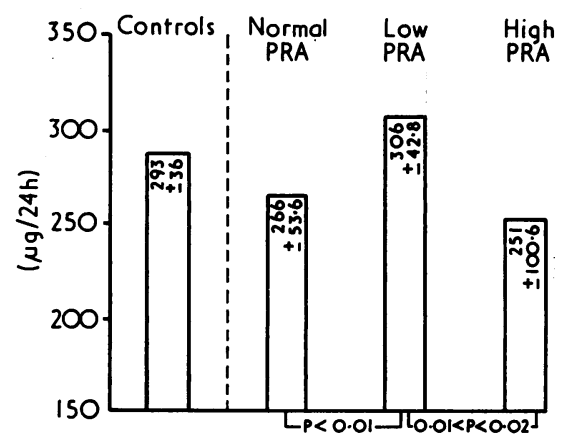

Fig. 2 Mean urinary dopamine excretion.

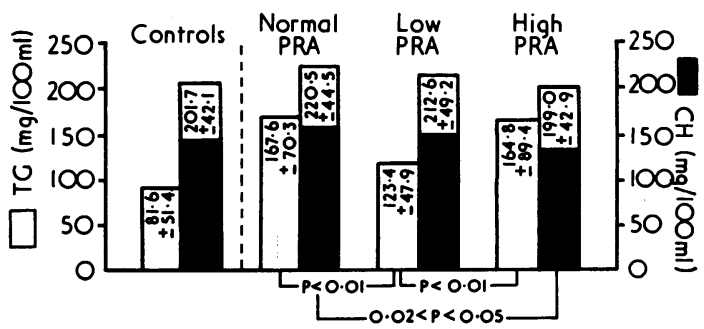

Fig. 3 Mean serum triglyceride (TG) and cholesterol (CH) levels. 
in all groups of patients were significantly higher than in the controls.

The mean values of fasting glucose did not differ significantly between the investigated groups of patients and the controls. However, there was a difference in the shape of the glycaemic curves; in patients with normal and low plasma renin activity the levels of glucose were statistically higher than in controls beginning $1 \frac{1}{2}$ hours after the glucose load, while in patients with high plasma renin activity a significant difference was found after $\frac{1}{2}$ hour and later.

The fasting level of glucose in patients with low plasma renin activity was statistically lower than in patients with normal plasma renin activity $(P<0.05)$. One hour after the glucose load glycaemia was significantly higher in patients with high plasma renin activity than in those with normal $(\mathrm{P}<0.01)$ and low $(P<0.02)$ plasma renin activity (Fig. 4$)$.

The fasting plasma immunoreactive insulin levels of patients with hypertension did not differ significantly from those of the controls. However, after the glucose load there was a significant difference between the patients and controls: in the normal plasma renin activity group-after $1 \frac{1}{2}, 2$, and $2 \frac{1}{2}$ hours, in the low plasma renin activity groupafter $1 \frac{1}{2}$ hours and later, and in the high plasma renin activity group after $\frac{1}{2}, 1,1 \frac{1}{2}$, and 2 hours.

The differences between the groups of patients with hypertension were statistically significant only 1 hour after the glucose load (Fig. 5).

Fig. 6 shows the results of dilute blood clot lysis time and euglobulin lysis time in the investigated groups of patients. Difference in euglobulin lysis time between low and normal plasma renin activity groups was statistically significant. In comparison with the control group, there were no significant differences in relation to dilute blood clot lysis time, while the euglobulin lysis time was significantly longer in patients with normal plasma renin activity than in controls.

\section{Discussion}

The results obtained in this study show that patients with essential hypertension and different plasma renin activity also show different hormonal and metabolic patterns. The question arises as to whether those differences may contribute to the clinical picture and the course of the disease. In the light of the complex nature of essential hypertension the answer to this question is not simple. However, it seems that some explanations may be suggested.

The differences in noradrenaline excretion may confirm the relation between the renin-angiotensin

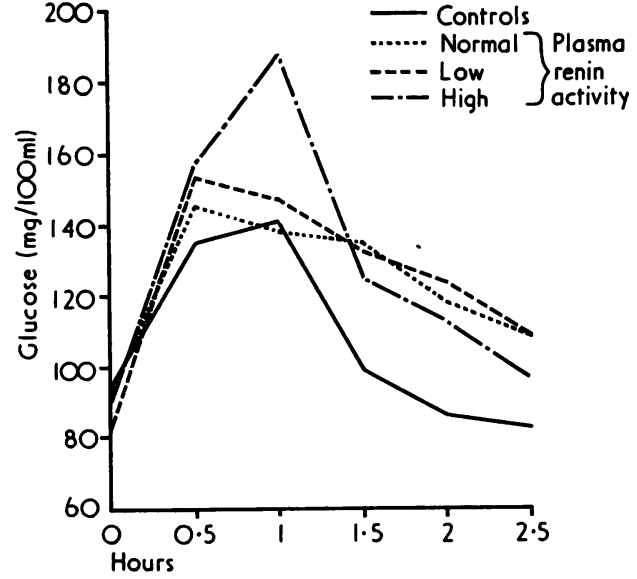

Fig. 4 Oral glucose tolerance test.

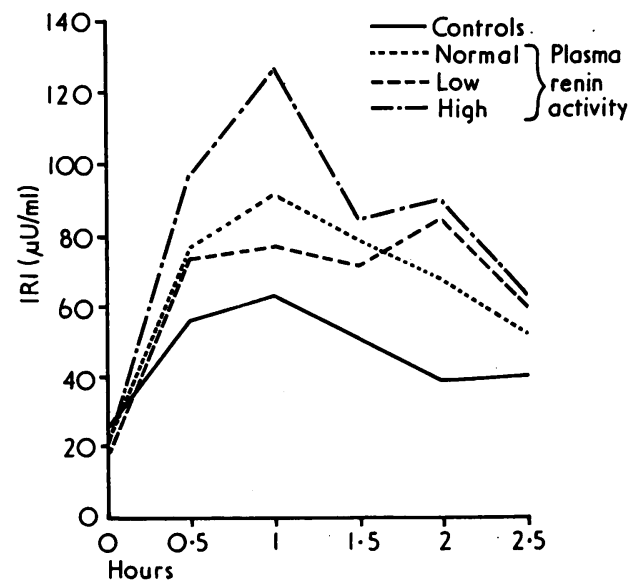

Fig. 5 Plasma immunoreactive insulin levels (IRI) after glucose load.

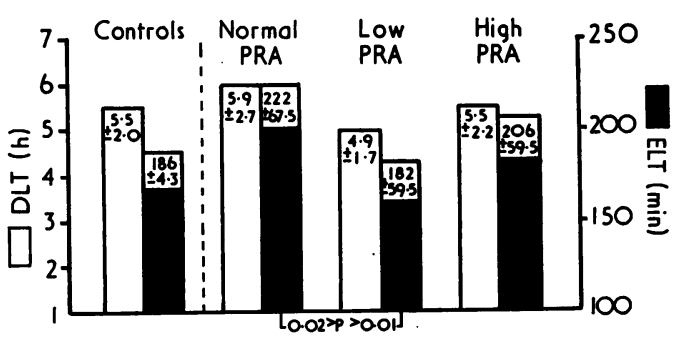

Fig. 6 Fibrinolytic activity measured by dilute blood clot lysis time $(D L T)$ and euglobin lysis time $(E L T)$. 
system and the sympatho-adrenal activity. Such a relation was suggested by various authors on the basis of experimental and clinical observations (Vander, 1965; Wathen et al., 1965; Michelakis et al., 1969; DeQuattro and Miura, 1973). Our results are in agreement with the observations of DeQuattro et al. (1975) who found a much higher percentage of hypertensive patients with raised catecholamine levels in the high renin group in comparison with groups of patients with low and normal plasma renin activity.

The differences in dopamine excretion are also interesting in view of the physiological properties of this amine. It is noteworthy that some authors observed the inverse relation between renin activity and dopamine excretion in certain physiological conditions connected with increased sympathetic activity (Cuche et al., 1974).

The high glucose and insulin levels in patients with high plasma renin activity may be related to the raised catecholamine secretion in these patients, which may be responsible both for the increase of endogenous insulin secretion and for impaired action of this hormone resulting in abnormal carbohydrate tolerance.

The differences in triglyceride levels and fibrinolytic activity between groups of patients with different plasma renin activity deserve special attention. The prolongation of euglobulin lysis time in patients with normal and high plasma renin activity in comparison with low renin group is related to higher triglyceride levels in these groups. It is known that the pre- $\beta$-lipoprotein fraction rich in endogenous triglycerides inhibits the plasminogen activator secretion in the blood vessel wall and its deficiency may cause inhibition of fibrinolysis (Spöttl et al., 1968). Both triglyceride increase and fibrinolysis inhibition may promote the development of atherosclerotic changes in blood vessels. It should be added that in patients with ischaemic heart disease the incidence of hypertriglyceridaemia and inhibition of fibrinolytic system is similar (Chakrabarti et al., 1968).

On the basis of the results of the study it is possible that the metabolic changes seen in patients with different plasma renin activity may be one of the factors responsible for the varying incidence of cardiovascular complications in these patients. However, in the light of present knowledge it is difficult to assess whether these differences are related to the pathogenetic heterogeneity of essential hypertension and whether they may influence the natural history of the disease.

This investigation was partially supported by Polish Academy of Sciences, Dep. VI.

\section{References}

Brunner, H. R., Laragh, J. H., Baer, L., Newton, M. A., Goodwin, F. T., Krakoff, L. R., Bard, R. H., and Bühler, F. R. (1972). Essential hypertension: renin and aldosterone, heart attack and stroke. New England fournal of Medicine, 286, 441-449.

Brunner, H. R., Sealey, J. E., and Laragh, J. H. (1973). Renin sub-groups in essential hypertension: further analysis of their pathophysiological and epidemiological characteristics. Circulation Research, 32-33, Suppl. I, 99-105.

Carlsson, A., and Waldeck, B. (1958). A fluorometric method for the determination of dopamine (3-hydroxytyramine). Acta Physiologica Scandinavica, 44, 293-298.

Chakrabarti, R., Hocking, E. D., Fearnley, G. R., Mann, R. D., Attwell, T. N., and Jackson, D. (1968). Fibrinolytic activity and coronary artery disease. Lancet, 1, 987-990.

Cramer, K., and Isaksson, B. (1959). An evaluation of the Theorell method for the determination of total serum cholesterol. Scandinavian fournal of Clinical and Laboratory Investigation, 11, 213-216.

Crane, M. G., Harris, J. J., and Johns, V. J. (1972). Hyporeninemic hypertension. American fournal of Medicine, 52, 457-466.

Cuche, J. L., Kuchel, O., Barbeau, A., Langlois, Y., Boucher, R., and Genest, J. (1974). Autonomic nervous system and benign essential hypertension in man: II. Circulatory and hormonal responses to upright posture. Circulation $\mathrm{Re}$ search, 35, 290-297.

DeQuattro, V., Campese, V., Miura, Y., and Meijer, D. (1975). Biochemical markers of sympathetic nerve activity and renin in primary hypertension. In Pathophysiology and Management of Arterial Hypertension, p. 23. Ed. by G. Berglund, L. Hansson, and L. Werkö. Lindgren and Söner AB. Mölndal, Sweden.

DeQuattro, V., and Miura, Y. (1973). Neurogenic factors in human hypertension: mechanism or myth? American fournal of Medicine, 55, 362-378.

Doyle, A. E., Jerums, G., Johnston, C. I., and Louis, W. J. (1973). Plasma renin levels and vascular complications in hypertension. British Medical fournal, 2, 206-207.

Fearnley, G. R., Balmforth, G., and Fearnley, E. (1957). Evidence of diurnal fibrinolytic rhythm. Clinical Science, 16, 645-650.

Januszewicz, W., and Wocial, B. (1975). Dopa, catecholamines and their metabolites in essential hypertension. Clinical Science and Molecular Medicine, 48, 295s-298s.

Laragh, J. H. (1973). Vasoconstriction-volume analysis for understanding and treating hypertension. The use of renin and aldosterone profiles. American fournal of Medicine, 55, 261-274.

Michelakis, A. M., Caudle, J., and Liddle, G. W. (1969). In vitro stimulation of renin production by epinephrine, norepinephrine, and cyclic AMP. Proceedings of the Society for Experimental Biology and Medicine, 130, 748-753.

Mroczek, W. J., Finnerty, F. A., and Catt, K. J. (1973). Lack of association between plasma-renin, and history of heart-attack or stroke in patients with essential hypertension. Lancet, 2, 464-469.

Niewiarowski, S. (1960). Krzepniecie krwi. Pañstwowy Zakad Wydawn Lekarskich, Warsaw.

Somogyi, M. (1952). Notes on sugar determination. Fournal of Biological Chemistry, 195, 19-23.

Spöttl, F., Holzknecht, F., and Braunsteiner, H. (1968). Inhibitors of the plasminogen-activation in patients with primary "carbohydrate-induced" hypertriglyceridemia. fournal of Atherosclerosis Research, 8, 821-826.

Vander, A. J. (1965). Effect of catecholamines, and the renal 
nerves on renin secretion in anesthetized dogs. American Fournal of Physiology, 209, 659-662.

Von Euler, U. S., and Lishajko, F. (1961). Improved technique for the fluorometric estimation of catecholamines. Acta Physiologica Scandinavica, 51, 348-356.

Wathen, R. L., Kingsbury, W. S., Stouder, D. A., Schneider, E. G., and Rostorfer, H. H. (1965). Effects of infusion of catecholamines and angiotensin II on renin release in anesthetized dogs. American fournal of Physiology, 209, 1012-1024.

Requests for reprints to Professor W. Januszewicz, Second Department of Medicine, Academy of Medicine, ul. Nowogrodzka 59, 02-006 Warsaw, Poland. 